\title{
La historia argentina al banquillo. Sobre los usos políticos del pasado y los regímenes de historicidad
}

Verónica Tobeña

\section{Resumen}

El artículo hace foco en los dos modelos historiográficos que están en la base de la controversia suscitada alrededor de la historia argentina, cuando a la salida de la crisis de 2001 vivida por ese país, un conjunto de libros sobre su pasado, cuyos autores presentan procedencias marginales o ajenas al mundo académico y el campo historiográfico que los avalen como historiadores, median en la recuperación del interés del público por el pasado, propiciando lo que algunos interpretaron como "un boom de la historia". El texto aporta argumentos para comprender la dispar acogida que el público brinda a divulgadores y profesionales de la historia y a partir del análisis plantea que ambos cánones no se configuran como opuestos solamente porque se diferencian en aspectos retóricos, de formato y/o metodológicos, sino que hay además tradiciones de las que cada uno de ellos son deudores e imágenes de la historia que funcionan de guía para ellos, que explican las diferencias que existen entre ambas concepciones de cómo debe hacerse la historia.

Palabras clave: historia argentina, historiadores profesionales, divulgación histórica, tradiciones historiográficas, regímenes de historicidad.

\section{Abstract}

Argentine history on the dock. About political uses of the past and historicality regimes

The article focused on two historiographic models that are on the basis of the controversy about the argentine history, when at the end of the 2001 crisis a set of books 
about his past, whose authors present marginal backgrounds or outside the academic world and the historiography that endorse as historians, mediate the recovery of public interest in the past, leading to what some interpreted as "a boom in history". The paper provides arguments for understand the uneven answers that public gives to amateurs and professional of the History and from the analysis suggests that both fees are not set up as opposites because they differ only in rhetorical, format and/or methodological aspects, but there are also traditions that each of them are debtors and images of history guide that work for them, explaining the differences between the two conceptions of how to do history.

Key words: argentine history, professional historians, historiographical best sellers, historiographical traditions, historicality regimes.

\section{Introducción}

El presente artículo analiza las diferencias que mantiene la historia nacional que escriben los protagonistas de la contienda historiográfica desatada a la salida de la crisis de 2001 en la Argentina que, tomando como escenario la prensa gráfica nacional, enfrentó a académicos y divulgadores de la historia en virtud de la impugnación que suscitó a los primeros, el éxito de público conseguido por los libros y producciones audiovisuales de los segundos, en un contexto fuertemente marcado por incertidumbres sociales.

Nuestra indagación sugiere que las condiciones de lectura que presentan los libros de historia que escriben los divulgadores están en las antípodas de las que caracterizan a la historiografía académica, pero ambos cánones no se configuran como opuestos solamente porque se diferencian en aspectos como el retórico, el epistemológico y/o el metodológico, sino que hay además tradiciones de las que cada uno de ellos son deudores e imágenes de la historia que funcionan de guía para ellos, que explican las diferencias que existen entre ambas concepciones de cómo debe hacerse la historia. En este sentido, la propuesta del artículo es analizar ambas vertiente historiográficas intentando, tanto iluminar en qué tradición se inscribe cada uno de estos modelos haciendo un poco de historia de la disciplina, como procurando establecer qué tipo de concepción de la historia domina en cada una de las posturas que están representadas en la disputa. A su vez, interesa analizar ambos modelos historiográficos a partir de lo que François Hartog denomina régimen de historicidad $(2007,2010)$, pues esta noción se concentra en la experiencia del tiempo que existe en una época dada. 


\section{Los términos y el contexto de la controversia}

La crisis que sacudió a la Argentina en el año 2001 se vivió y se significó socialmente como una de las crisis más profundas y desgarradoras de la sociedad, por sus ribetes políticos, sociales, económicos y culturales. Pero más allá de los interrogantes que abre la crisis en el plano político y económico más coyuntural, este periodo está signado por la emergencia de una pregunta más estructural que es recurrente en los periodos de la historia determinados por cambios y/o rupturas: ¿qué significa o qué implica ser argentinos? (Sarlo, 2001; Grimson, 2011). A este impulso por revisar el pasado y por redefinir las identidades al que empujan las crisis parece estar respondiendo la masiva adhesión que encuentran un conjunto de producciones bibliográficas que tienen por objeto precisamente la reflexión sobre el significado de ser argentino en clave histórica. Se trata de un conjunto de libros que narran la nación con una repercusión sobresaliente, ${ }^{1}$ escritos por autores que funcionan como "referentes de opiniones políticas generales que se enuncian desde el ámbito más amplio de la cultura" (Semán, Lewgoy y Merenson, 2007: 299).

Un dato relevante de la controversia ${ }^{2}$ que suscitan entre los historiadores profesionales estos exitosos relatos de nuestro pasado es que sus autores no tienen formación formal en la disciplina historiográfica, como en el caso de Lanata y O'Donnell, y cuando la tienen, como en el de Felipe Pigna, la misma es deslucida. Lo que es común a estos autores de best-sellers es un

${ }^{1}$ Entre las producciones más conspicuas se encuentran las de Felipe Pigna, entre las que están la saga de los libros Los mitos de la historia argentina que actualmente va por su quinto tomo, entre otros. Además, todas las producciones que este historiador realizó para la TV (la más popular es "Algo habrán hecho por la historia argentina") que luego se plasmaron en DVD de amplia circulación entre el público general con fuerte llegada a las escuelas. Sus productos y sus intervenciones radiales también constituyen un polo de atracción para quienes se interesan por la historia. De la pluma de Jorge Lanata cabe citar Argentinos I y II, dos tomos de 500 páginas cada uno, de los cuales existe una versión de bolsillo y otra pedagógica como lectura recomendada para enseñanza media. También Lanata tuvo una amplia repercusión de público con el libro ADN. Mapa genético de los defectos argentinos. La producción historiográfica de Mario "Pacho" O’Donnell, por su parte, se presenta explícitamente como una propuesta orientada a iluminar aspectos escamoteados u ocultos de la historia oficial argentina. Dentro de la serie La historia argentina que no nos contaron publicó El grito sagrado (1997), El águila guerrera (1998), El Rey Blanco (2000), y Los héroes malditos (2004), todos ellos encaramados en las listas de best-sellers.

${ }^{2}$ Los argumentos más sobresalientes que académicos e intelectuales despliegan en contra de la divulgación histórica pueden consultarse en Gelman (2007), Canavese y Costa (2005), Mendelevich (2005), Palomar (2005), Paredes (2005), Romero (2003), Romero (2004a; 2004b; 2004c; 2004d), Sabato y Lobato (2005), San Martín (2007), y Sarlo (2006). 
recorrido fuertemente marcado por su presencia en los medios masivos de comunicación y una autoridad cultural que deviene del papel que su paso por medios como la televisión, la radio y/o la prensa gráfica les confieren. En este sentido, es interesante evocar aquí la denominación adoptada por las investigaciones del sociólogo argentino Pablo Semán para caracterizar a estos autores y sus libros, donde los bautiza como "historiadores de masas".

Ahora bien, ¿cuáles son las objeciones que realizan los académicos a la historia de los divulgadores que contornean la controversia en cuestión? Las críticas más sobresalientes son las siguientes:

- Dicen que hablan la lengua del mercado y que es escuchada por eso, que adoptan una prosa provocativa y una militancia declarada.

- Señalan un mal uso de las fuentes documentales (que son escasas, que se incorporan de forma acrítica y se seleccionan entre documentos ya perimidos).

- Sostienen que no captan la especificidad y la singularidad de los periodos que analizan, porque auscultan el pasado partiendo de la fórmula "ayer es igual que hoy" y de este modo homologan el pasado al presente y así borran los condicionamientos de época que intervienen en el devenir histórico.

- Advierten una concepción pobre de la historia: se presentan los hechos como resultado del accionar de héroes y villanos. Esta historia desprecia los procesos, sujetos colectivos y estructuras. Brillan por su ausencia las dimensiones del orden de lo social, lo económico, lo cultural y/o lo simbólico.

- Denuncian que lo que articula el relato de estas historias es la corrupción, la traición eterna, el complot, la conspiración.

- Los ubican en la corriente del "revisionismo histórico" pero señalan sus diferencias: las obras de los revisionistas circularon por espacios alternativos y de confrontación; en cambio, los neo-revisionistas construyen su prestigio gracias al apoyo de los medios masivos. Lo que en aquéllos era herramienta de lucha en éstos es una mercancía, dicen.

Entre los argumentos que los divulgadores esgrimen en su defensa, merecen mención:

- El que plantea que esas críticas confunden divulgación con vulgarización de la historia, y que si se los critican es porque se está en contra de que la historia se divulgue en virtud de una concepción elitista del saber. 
- "Cuando se me critica que comparo el pasado con el presente el punto que me gustaría debatir es qué se entiende por Historia", replica el adalid de este fenómeno en torno a la historia, Felipe Pigna. Para él la historia es una herramienta, un instrumento para transitar el presente, para entender lo que pasa hoy. Dice que "tiene una utilidad terapéutica, trabaja con el pasado para mejorar el presente", que es una materia instrumental, sirve para la vida, para leer el diario.

- Dicen que no usan la historia para hablar del presente sino que es inevitable despojarse de la época en la que uno está a la hora de hacerle preguntas al pasado.

- Discuten el consenso que comparten los académicos en cuanto al lugar ideológicamente neutral desde el que debe escribirse la historia. En su opinión no hay posibilidad de escindir la práctica histórica de la política porque todo historiador "parte de una subjetividad, de su presente, su cotidianeidad y también de su ideología".

- El conflicto con la historia académica es visto desde aquí no como resultado de desacuerdos metodológicos sino, fundamentalmente, producto de las matrices ideológicas divergentes en las que se asientan unos y otros. Los mediáticos no reniegan de defender con su historia lecturas nacionalistas e intereses populares tal como les endosan los académicos, pero a su turno se encargan de precisar que los intereses que sus críticos protegen amparados en su "neutralismo pseudo-académico" se inscribe en la matriz liberal. De esta manera, la facciosidad y la concepción de la historia como lucha entre buenos y malos de la que era acusada esta historia surge de entender a la misma como una práctica política, antes que científica. Desde esta perspectiva, incluso la práctica histórica realizada con arreglo a la objetividad científica que manda la academia, a pesar de su lenguaje neutral y su tono equilibrado, es fuertemente política, porque su aparente imparcialidad no sirve más que para reproducir el status quo y con él la ignorancia sobre el pasado que le permite a los poderosos perpetuarse en el poder con la anuencia de un pueblo guiado por la mentira.

- No sólo contradicen a los académicos en el modo que ligan historia y política, sino que lo hacen cuando proponen incluir en la agenda de la historiografía argentina a la historia reciente. ¿Para qué serviría la historia sino para entender mejor la realidad?, razonan.

El saldo que deja la confrontación entre académicos y divulgadores de la historia permite delinear dos cánones historiográficos, que podemos identificar como canon de los divulgadores y canon de los historiadores profesio- 
nales. ${ }^{3}$ El canon de los divulgadores constituye un tipo de discurso que no se escribe con arreglo a los preceptos que marca el ideal científico hegemónico, y propone un acercamiento a su objeto explícitamente colonizado por la política; una retórica simple, sin tecnicismos, afecta a los guiños hacia el lector y fórmulas efectistas; una prosa con tintes provocativos y militante; un formato afín al que domina en los medios masivos de comunicación; espacios de circulación extra-académicos y uso de soportes no sólo literarios sino también de medios como la televisión, la radio, DVD y CD, y las revistas no especializadas y de divulgación masiva; medios masivos de comunicación y gran público como focos de legitimación; un pensamiento político explícitamente antiliberal, con resonancias de la corriente nacional y popular.

El canon de la historia profesional, por su parte, es un discurso histórico producido con arreglo a los presupuestos epistemológicos que plantea la disciplina y que se esfuerza por mantenerse autónomo de la política; una retórica específica, que es afecta a un lenguaje técnico, terminología que se pretende neutral y un tono aséptico; un formato narrativo consustanciado con las reglas del arte impuestas por la disciplina; espacios de circulación casi exclusivamente académicos y uso del libro y las revistas especializadas como soporte dominante; la academia (centros de investigación, universidades) y sus pares constituyen sus principales dadores de legitimidad; y una relación implícita o escamoteada con las afinidades político-ideológicas que impregna a estas historias, que podría caracterizarse como una "ideología científica".

\section{Dos tradiciones historiográficas y un nudo temático: la historia científica y la historia militante frente a la última dictadura militar}

Ahora bien, si se trata de distinguir dónde se hunden las raíces de las líneas en pugna que abren estos historiadores de vertiente contraria resulta insoslayable considerar la especificidad del discurso historiográfico. Esa singularidad de la historia está dada por su objeto, el pasado; y el pasado, sobre todo cuando se

${ }^{3}$ Desde ya, ni toda la historiografía argentina que se inscribe en la denominada "divulgación histórica" ni la que se produce bajo la influencia de la "historia académica y/o profesional" adopta las mismas posturas que asumen los contendientes que participan de la controversia de la que nos ocupamos aquí. Si simplificamos el campo historiográfico dividiéndolo en dos vertientes más bien paradigmáticas es porque así quedan delineadas las fuerzas en esta polémica, de modo que esta división sólo vale para caracterizar a quienes participan de ella, es decir que no alcanza necesariamente a aquellos agentes del campo historiográfico que se mantienen al margen de esta disputa. 
reconstruye teniendo como eje articulador a la Nación o el Estado nacional, como es el caso de los relatos históricos de la controversia de la que aquí nos ocupamos, involucra a todos como sociedad, porque contribuye a dar carnadura histórica a una identidad nacional y a ofrecer una imagen de su pasado de la que puede extraerse quiénes son sus miembros y a dónde se dirigen. La historia nacional da contextura y densidad temporal al país que se es hoy, para dar o quitarle legitimidad al camino recorrido y otorgarle o restarle valor a las opciones con las que hoy se cuenta. ${ }^{4}$ En este sentido, la historia es importante no sólo porque provee de un pasado común y porque cuenta cómo llegamos al presente sino porque justifica el camino a transitar hacia el futuro (Jelin, 2001; Carretero y Voss, 2004; Carretero, Rosa y González, 2006).

Es importante recordar que el proceso de consolidación y de organización del saber histórico se produce en el siglo XVIII de la mano del Estado, a través de la operación de disciplinamiento de los saberes estudiada por Foucault (2000: 163) que culmina en la formación de un discurso funcional, elaborado, sistemático, conceptual y unitario como es el científico, con mecanismos de legitimación y calificación del saber que le son específicos y que por tanto propician nuevos modos de relación entre el saber y el poder.

La especificidad de la historiografía está dada entonces por tratarse de un tipo de discurso tanto modulado por, como modulador del campo político; un discurso que se presta al uso político tanto a favor como en contra de una relación de fuerzas dada, del statu quo (Myers, 2004; Cattaruzza, 2007; Pittaluga, 2010).

Ahora bien, por un lado resulta importante establecer cuáles son los hechos del pasado argentino que se constituyen en ejes de la controversia en la disputa entre divulgadores y académicos de la historia que tiene lugar a la salida de la crisis de 2001; es decir, precisar sobre qué acontecimientos del pasado se producen lecturas que reponen preocupaciones políticas y valoraciones de corte ideológico en el discurso de la historia. Por otro lado, resulta importante tener en cuenta cómo fue pensado y cómo intentó ser constituido el campo historiográfico en la Argentina, puesto que la arquitectura del campo resultante de estos procesos puede tener consecuencias respecto al modo en que se ponderan algunas dimensiones del pasado.

Los modelos que hacen a buena parte de la contextura que presenta la historiografía en la Argentina son el modelo de excelencia académica y el modelo de la universidad politizada de los años setenta; esto es, la contraposición entre la historia científica y la historia militante o política (Pittaluga, 2010: 129-130).

\footnotetext{
${ }^{4}$ Véase el concepto de tradición selectiva en Williams (1980).
} 
La "historia científica" recibe esta denominación al establecer para sí criterios "científicos" 5 para evaluar la calidad de una producción historiográfica. Entre esos criterios que permiten dirimir la solvencia de un texto se cuentan: la explicitación de lo que en la jerga de las ciencias sociales se denomina "estado del arte" del tema que es objeto de análisis, de modo de ofrecer al lector las contribuciones que la disciplina ya ha realizado sobre el mismo; la presentación de la evidencia y de las fuentes en las que se basa el estudio; rigurosidad en el análisis; el manejo de un adecuado aparato de referencias bibliográficas; una presentación temática sobria, sin pretensiones narrativas (uso preciso de los términos, lenguaje estricto, conceptos afinados); el respeto a la distancia con el objeto de estudio que debe traducirse en asepsia valorativa y en el mantenimiento de la autonomía intelectual de las preocupaciones y las urgencias de la política (Pittaluga, 2010; Di Meglio, 2012; Sazbón, 2012). Esta última exigencia es la que excluía de la agenda historiográfica la posibilidad de hacer historia del pasado reciente, puesto que su cercanía con el presente hace de ese pasado algo todavía actual. A este respecto el historiador Roberto Pittaluga considera que "es muy difícil hacer historia del pasado reciente sin hablar, al mismo tiempo, políticamente. Porque ese pasado no se ha convertido, aún, en un 'objeto frío' [...], es decir, todavía no es un 'pasado fijo', como lo requiere o lo concibe la historiografía hegemónica, y por ello es difícil que sea tratado por esa misma historiografía” (Pittaluga, 2010: 130-131).

La denominada "historia militante", por su parte, se contrapone a la anterior en cada uno de estos aspectos. La calidad de un texto histórico está dada para esta perspectiva por su compromiso con la política y su capacidad para revelar los grandes conflictos que motorizan la historia. Esta tradición hace del posicionamiento político del historiador una condición, y como pone el acento en la politicidad de la práctica histórica más que en su cientificidad; para ella todos los reparos metodológicos, los recaudos del lenguaje, la neutralidad valorativa y las prescripciones que tienen que ver con imponer limitaciones en lo que hace a los aspectos narrativos de la historia no son válidos. Tampoco respeta la premisa que reza que la historia debe mantener cierta distancia crítica y temporal con su objeto de estudio. Lo que guía el trabajo historiográfico de esta corriente es una "partición esencial de lo histórico en campos conflictivos" (Fernández, 2012). Por ejemplo, para el historiador Omar Acha, la "historia militante" reconstruye una "historia argentina que muestra que desde 1810 hubo 'dos modelos de país': uno de corte popular, integrador, plebeyo, nacionalista; otro elitista, excluyente, extranjerizante” (Acha, 2012).

${ }^{5}$ Criterios que elabora tomando como modelo las ciencias sociales. 
Ahora bien, en el tratamiento que ambas corrientes hacen de algunos hechos o acontecimientos de nuestro pasado se vislumbra a nuestros ojos la condensación de esas divergencias. Uno de esos hechos históricos que funcionan como nudo temático capaz de sintetizar de forma elocuente las diferentes concepciones del quehacer histórico en que se basan estos dos modelos es la última dictadura militar. Esto no sólo se constata en el hecho de que es en torno al tratamiento de este tópico que se montan muchos de los señalamientos que los académicos hacen a los divulgadores, ${ }^{6}$ sino que también se rastrea en el modo conflictivo en que el campo académico post-dictatorial se relaciona con esa historia reciente; pues como dice Roberto Pittaluga, "este último se constituyó sobre la base de una casi total exclusión del pasado inmediato, de su propio pasado reciente como campo académico, y también del pasado político reciente de la Argentina" (Acha, 2012: 124). De modo que creemos prudente analizar las críticas a los divulgadores que involucran el tema de la última dictadura militar de parte de los académicos considerando este dato.

¿Por qué en general la historia académica expulsó el pasado reciente de su agenda cuando se institucionalizó en los años ochenta? $?^{7}$ El de la transición democrática constituyó uno de esos momentos históricos en que las relaciones entre política y campo intelectual se estrechan, en que las convicciones y las urgencias de uno se replican en los valores y en las preocupaciones del otro. Y la clave de lectura que promovió el campo político para encarar la relación entre la transición democrática y el pasado reciente consistió en la negación de la historia que se acababa de vivir como hija de procesos previos y propios, declarando así las atrocidades vividas durante el periodo huérfanas de cualquier tradición democrática precedente. De modo que se hace frente a la transición democrática recortando una tradición democrática completamente ajena a la historia de violencia política que la precedía, porque al pensar a la última dictadura militar como un paréntesis de su historia, se piensa en la

${ }^{6}$ Por ejemplo, los pueblos originarios diezmados por la conquista al desierto son los primeros desaparecidos y a ellos les sigue Mariano Moreno, porque su cuerpo sin vida fue arrojado al mar; la fecha de inicio del Congreso de Tucumán que es un 24 de marzo merece una reflexión sobre el inicio de la dictadura; La ley de Amnistía de Rivadavia se equipara a las leyes de Punto Final y Obediencia Debida y el indulto a los militares de la dictadura.

${ }^{7}$ Desde luego, hay excepciones. Roberto Pittaluga destaca el "enorme esfuerzo a contracorriente" que realizan pequeños colectivos de investigadores que se vienen dedicando al pasado reciente desde hace varios años, en distintos puntos del país (La Plata, Rosario, Buenos Aires, entre otros), pero pondera que "mirado desde el conjunto del espacio historiográfico académico, representaron una corriente que estaba como en una especie de latencia, de trabajo permanente y silencioso, y ciertamente marginal" (Pittaluga, 2010: 131). 
posibilidad de erradicarla totalmente de la sociedad argentina. Y esta lectura tuvo un impacto inmediato en el campo historiográfico, que legitimó y reprodujo esta interpretación desde las producciones provenientes de las posiciones hegemónicas al interior del campo. En palabras del historiador Roberto Pittaluga, el camino que debía seguir la transición democrática según esta lectura era más o menos así:

Este es el momento de recuperar la "república perdida", y de saldar las cuentas con aquellas otras tradiciones de la historia argentina que impidieron la constitución de una república democrática como estaba en los orígenes, en el destino, en los propósitos de los padres fundadores, etc. [...] La formulación más concisa, clara y contundente de esto es la llamada "teoría de los dos demonios". Esa era una de las figuras discursivas que actuaron como fondo para la configuración del campo historiográfico, un fondo o contexto que de alguna manera modelaba las posibilidades de lo decible e investigable en términos históricos. (Pittaluga, 2010: 125)

Otros intelectuales, como Beatriz Sarlo y Juan Carlos Torre, hacen descansar en las características cruentas del pasado reciente y en la dimensión biográfica que ese pasado tiene para los historiadores, las razones para abstenerse de abordarlo desde el trabajo historiográfico. Sarlo afirmaba que los años sesenta y setenta probablemente estuvieran "demasiado cerca", y fueran a la vez "demasiado terribles" como para hablar de ellos (Sarlo, 1994: 172). La reflexión de Juan Carlos Torre al respecto es elocuente de la moderación que muestran las consignas intelectuales tras la experiencia de la violencia de los años setenta: "Después de haber abogado por la revolución — dice- nos hemos desplazado a pedir un país normal, donde simplemente estemos al abrigo de las disrupciones, de los quiebres, del espectáculo sobrecogedor del abismo" (Torre, 2004: 196). El historiador Omar Acha plantea que este ideal del "país normal" que sistematiza la reflexión de Torre constituyó la "doxa" de la disciplina. De modo que el sentido de la práctica historiográfica estaba para los académicos fuertemente condicionado por la historia que se acababa de vivir (Acha, 2008: 171), en sintonía con los supuestos, las premisas y los valores progresistas que por entonces instituía el campo político, que quedan resumidos en las ideas de "modernización, integración, inclusión, desarrollo y democratización".

Ahora bien, en relación con las consecuencias que la operación postdictatorial tiene para el campo historiográfico académico, que lo llevó a una búsqueda de asepsia cientificista tomando como el anti-modelo la tradición de la historia militante de décadas anteriores, de la cual terminó por desmarcarse (Di Meglio, 2012), hay dos cuestiones a señalar. La primera tiene 
que ver con la creciente profesionalización del campo ${ }^{8}$ y su progresivo desplazamiento de la figura del intelectual a la del especialista (Sarlo, 1985). La otra cuestión es la ilusión de cientificidad que las reglas y las pautas disciplinares que va dándose el campo contribuyen a generar y la consiguiente sensación de despolitización de la actividad que las mismas despiertan (Di Meglio, 2012). Huelga decir que usamos las expresiones "ilusión de cientificidad" y "sensación de despolitización" para subrayar la artificiosidad del discurso histórico, para acentuar que esta neutralidad que destila la historiografía producida con arreglo a las pautas que dicta la academia es producto de los efectos del discurso y se debe en buena medida a las formas que adopta el mismo.

La constitución del campo historiográfico que propició el régimen democrático abrazó una concepción de la disciplina histórica asociada a un quehacer intelectual emancipado de las demandas políticas inmediatas, que desde entonces se arrojaron al desprestigiado terreno de la "ideología". Pero en rigor, este gesto que buscaba producir un corte con la imbricación con la política tan habitual en las décadas precedentes, no constituye un movimiento tendiente a la despolitización sino más bien a la repolitización. En efecto, al abogar por un "país normal" y un paquete de valores que se identifican con cierta conciencia progresista, la política no desaparece. Los presupuestos que por entonces sostiene la historiografía no podrían estar menos condicionados por la historia que se venía de vivir. Lo que desaparece es el posicionamiento explícito en los textos, desaparece la suerte de fetichización de la política que se encontraba en la historia militante precedente. Pero la visión del autor está en los textos, los permea.

Los estudios citados dan cuenta de que el escenario que se abre con la reinstalación de la democracia en 1983 ofrece un clima incompatible con la tradición historiográfica militante, la cual suele conllevar una prosa provocativa y preñada por el conflicto esto es, formas discursivas y lecturas del pasado que intentaban dejarse atrás desde la matriz democrática que se reivindica desde la política oficial. Los marcos establecidos por el gobierno de Alfonsín, en cambio, sí constituyeron condiciones favorables a la tradición científica de la historia. En la Argentina este modelo tenía como antecedente

${ }^{8}$ Dicha profesionalización tiene también que ver con los nuevos dispositivos de regulación científica del sistema académico, basados en una estricta evaluación respecto a la metodología, al número de artículos a publicar, a los circuitos y soportes por los cuales se hace circular los resultados de las investigaciones, etc. El ejercicio del oficio histórico bajo las pautas que prescriben estas regulaciones suele ser tan exigente que constituye en sí mismo una fuente de identificación para quienes se someten a ellos y, por ende, motivo para suscitar solidaridades corporativas fuertes. 
la "historia social y cultural", que de la mano de José Luis Romero había desembarcado en la universidad a instancias de la llamada "Revolución Libertadora" en $1955^{9}$ (Myers, 2004; Devoto, 2010; Acha, 2009; Cernadas y Lvovich, 2010). En los ochenta esta corriente historiográfica se recupera y la disciplina emprende la marcha firme hacia la profesionalización, siguiendo de cerca para su "puesta a punto" las corrientes historiográficas imperantes en países como Estados Unidos, Inglaterra y Francia (Di Meglio, 2012). La tendencia hacia la profesionalización se profundiza y se expande constituyéndose en el modelo hegemónico.

El escenario post-crisis en el que surgen las divulgaciones históricas de la controversia es muy distinto al que se recortaba en la década del ochenta. Los ecos que había dejado la violencia política de los años setenta ya no resonaban del mismo modo y más de 25 años ininterrumpidos de régimen democrático habían revelado que eso de que "con la democracia se come, se cura y se educa"10 no era más que un eslogan. La "teoría de los dos demonios" que había gozado de un formidable consenso social comenzaba a ser objetada como verdad universal o definitiva.

Sabemos que cuando el espacio de la política se abre a la contingencia como en ese momento, la posibilidad de disputar la conducción de ese espacio resulta más factible que en periodos de estabilidad y solidez institucional. Lo mismo ocurre con la historia: con la puesta en cuestión de liderazgos y acuerdos políticos entran en crisis las cosmovisiones en las que éstos se sostenían y apoyaban, y las evaluaciones históricas imperantes caen en desprestigio.

Una cartografía de la historiografía argentina nos muestra un campo heterogéneo, que a medida que va edificándose se puebla de líneas teóricas, políticas e ideológicas variadas. En ella se destacan dos momentos que son importantes para nosotros como antecedentes de la disputa de la que aquí nos ocupamos, pues en ella se reeditan conflictos en torno a la definición historiográfica legítima y se reactualizan dos evaluaciones históricas divergentes en un marco de crisis y de cambios políticos abruptos y violentos, como fueron los golpes militares de 1930 y de 1955 .

${ }^{9}$ La llamada "Revolución Libertadora" fue el eufemismo adoptado por los perpetradores del golpe al gobierno de Juan Domingo Perón en el año 1955 y a partir del cual se instalan en el poder proscribiendo al peronismo de la vida política institucional.

10 "Con la democracia se come, se cura, se educa" se convirtió en los ochenta en una frase célebre del entonces presidente argentino, Raúl Alfonsín, y con la cual el mandatario buscaba acentuar el poder de la democracia para subsanar las desigualdades sociales frente a la opción de la violencia que había representado la última dictadura militar. 
El primero vio nacer a los revisionismos históricos, ${ }^{11}$ en cuya vertiente de orientación yrigoyenista ${ }^{12}$ y antiimperialista parecen abrevar, en parte, la historia que aparece en las divulgaciones históricas de la controversia que, como aquéllos, representa una alternativa a la historiografía hegemónica en la universidad, que en el treinta estaba encarnada por la Nueva Escuela Histórica, ${ }^{13}$ identificada con una manera de hacer historia profesional, de corte liberal y de la cual se nutre la versión oficial de la historia.

El segundo momento, coincidente con el golpe al peronismo del 55, es el que le permite a la renovación historiográfica, que se estaba dando en dicho campo de la mano del historiador José Luis Romero, arribar a espacios institucionales que les habían sido proscriptos por el peronismo, como la universidad. En una tradición progresista, la "historia social y cultural" que introduce Romero tiene en su horizonte la intención de refundar la universidad reformándola académica y políticamente. La corriente de la "historia social" se propone renovar a la historiografía apoyándose en los aportes de las ciencias sociales, fundamentalmente de la economía y la sociología (Acha, 2008).

Los años posperonistas también son importantes para el ascenso del revisionismo, ya que durante esta etapa dicha corriente logra su mayor expansión. Si bien la universidad les seguiría resultando hostil, la coyuntura cultural

${ }^{11}$ En la Argentina, el revisionismo histórico es una corriente historiográfica orientada a modificar la visión de la historia, enfrentando su versión del pasado con la historia tradicional que en ese país predominó desde mediados del siglo XIX. En particular, se ha orientado a defender la figura de los caudillos federales, considerados como símbolos de atraso político y cultural, fundamentalmente de Juan Manuel de Rosas, y a los conquistadores y colonizadores españoles, a los cuales el liberalismo del siglo XIX había estigmatizado y responsabilizado de todos los males. Existen distintas vertientes dentro del denominado revisionismo histórico y cada una de ellas plantea una postura específica que la diferencia de las restantes. Su denominador común es la intención de revisar lo que denominan "la historia oficial" y de revelar la verdad que ésta escamotea.

${ }^{12}$ Hipólito Yrigoyen fue dos veces presidente de la Argentina entre 1916-1922 y 19281930, representando a la Unión Cívica Radical (UCR). Con su primer mandato concluye el periodo conservador. Las elecciones que dieron triunfo a Yrigoyen en 1916 fueron las primeras que se realizaron a nivel nacional bajo los auspicios de la llamada Ley Sáenz Peña (ley electoral de 1912), que imponía el voto universal, secreto y obligatorio. En 1928 Yrigoyen fue electo presidente del país por segunda vez por una abrumadora mayoría en una elección conocida como "el plebiscito". Su periodo de gobierno quedó inconcluso como consecuencia del golpe de Estado producido el 6 de septiembre de 1930, que encabezó el general José Félix Uriburu y dio comienzo a la llamada "década infame".

${ }^{13}$ La profesionalización de la tarea de los historiadores en Argentina se inició a principios del siglo XX, con un grupo heterogéneo de historiadores a quienes se denominó "Nueva Escuela Histórica". Entre ellos se encontraban Luis María Torres, Emilio Ravignani, Diego Luis Molinari, Rómulo Carbia, Ricardo Levene, Narciso Binayán. En general, no tenían formación profesional específica pero fueron los creadores de la historiografía profesional en la Argentina. 
sí constituyó un marco favorable para fijar sus raíces, ya que el reservorio peronista significaba ahora un enorme público "en disponibilidad" (Devoto y Pagano, 2009: 278).

En suma, lo que es común a las distintas corrientes historiográficas que fueron complejizando el campo de la disciplina a lo largo de su historia y ampliando la variedad de sus tradiciones intelectuales es su emergencia en tres contextos de crisis de la historia política argentina. Dos de esos momentos corresponden a dos golpes militares que derrocaron a los dos gobiernos más populares de la historia argentina, los de Hipólito Yrigoyen y Juan Domingo Perón, y el tercero refiere al retorno a la democracia de la mano del radical Raúl Alfonsín tras años traumáticos, que no sólo incluyen un gobierno militar de facto, sino que contienen terrorismo de Estado, violencia política y hasta una guerra. Los revisionismos surgidos a fines de la década del treinta, los revisionismos que afloran en el año 55 y que se sostienen con éxito a lo largo de la década siguiente, la historia social que conquista la universidad en el año 55, y la definitiva instalación de la historia profesional que propicia la transición democrática iniciada en 1983, tienen como denominador común el hecho de encontrar en un escenario atravesado por la incertidumbre política y social las condiciones para su emergencia.

Luego, existen ciertos aires de familia entre algunos de ellos. En términos epistemológicos, una serie podría establecerse, por un lado, entre la historia social del 55 y la historia profesional del 83 y, por otro lado, entre los revisionismos de las décadas del treinta, los de la del cincuenta, sesenta y los libros de Pigna-Lanata-O'Donnell del siglo XXI. ${ }^{14}$ Ciertamente, el humor revisionista de estos últimos libros fue aludido en el análisis y consiguiente crítica de los mismos realizado por algunos historiadores académicos, que incluso llegaron a referirse a ellos como "neo-revisionismo". La ubicación de dichos best-sellers en el linaje revisionista tiene que ver con la identificación de motivos comunes, como el antiimperialismo, la oposición a un relato histórico que se denomina "historia oficial", la adscripción a un modelo conspirativo de la historia y la derivada autopostulación como la operación histórica que viene a denunciar la alianza oculta existente entre el saber y el poder para someter al "pueblo". Pero la asociación de estas divulgaciones históricas con la tradición revisionista también se funda en otras afinidades, como que en la base de ambas experiencias editoriales está la búsqueda de una explicación capaz de generar algún tipo de respuesta, tanto a la crisis política como a los

${ }^{14}$ Nos referimos a estos tres autores de forma indiferenciada porque así se refieren a sus libros los académicos cuando los hacen blanco de sus críticas, pero cabe consignar que entre ellos y sus obras existen muchas diferencias. 
cambios sociales y culturales introducidos por la primera, y por ello se emparentan en que unas y otras obras utilizan el pasado como excusa para hablar del presente. También en el hecho de que ambas recibieron una respuesta masiva del público, se forjaron y circularon por espacios extraacadémicos e inspiraron la reprobación de las voces de la academia. Sin embargo, aunque los académicos fueron uno de los propiciadores de la asociación entre "los libros de la controversia" y el revisionismo, también son ellos quienes impugnan la inscripción de los primeros en el linaje que constituyen los segundos, puesto que destacan su calidad sensiblemente inferior, sus resortes comerciales por oposición a las convicciones políticas que motivaban a los revisionistas del siglo pasado, y la ausencia en los últimos de alternativas y de gestos propositivos que propicien alguna tradición política en reemplazo de los panteones que desmantelan con sus interpretaciones.

\section{La última dictadura militar como nudo temático}

Más allá de las diferencias que distancian a "los neo-revisionistas" de los revisionistas del siglo pasado, creemos que lo que introduce una variante, un salto cualitativo entre ellos, es el hecho de que los best-sellers contemporáneos cuentan con la posibilidad — y la aprovechan — de inscribir a la última dictadura militar en la serie de hechos deleznables que los esquemas revisionistas de la historia suelen plantear y señalar como aquellos que la llamada "historia oficial" se empeña en ocultar o en presentar desprovistos de sus rasgos más dramáticos y de la identificación de sus responsables. Es decir, en virtud de su posterioridad cronológica, la historia que escriben estos "neo-revisionistas" puede optar por convertir en objeto de su reflexión un pasado que por su cercanía temporal y por sus nefastas características despierta pasiones y odios, emociones al calor de las cuales no es recomendable emprender ninguna indagación sobre el pasado desde la postura sostenida por la "historia científica". Con la introducción de este pasado reciente en las lecturas conspirativas de la historia y con la acentuación del mismo que implica su uso como modelo y medida para juzgar otros hechos, reducen así a todos los conflictos que atraviesan a la historia argentina al planteo violento que asumieron las diferencias políticas por esos años. Ese planteo violento pertenece a un capítulo de la historia argentina al que justamente parece difícil encontrarle parangón con cualquier otro hecho histórico precedente. Dicho gesto no sólo es controvertido porque transgrede las reglas del método histórico que aconsejan esperar a que los hechos "se enfríen" para hacer de ellos un objeto de estudio, sino también porque vulnera la interpretación que 
había logrado hegemonizar al interior del campo historiográfico el espacio político-intelectual durante la transición democrática. Esto es, que no hay nada bueno que pueda salir de "ese" arcón de los recuerdos, que fue una etapa dominada por los "demonios".

A su vez, hay que apuntar que la presencia de alusiones a la dictadura militar de parte de estos libros (para afirmar, por ejemplo, que Mariano Moreno es nuestro primer desaparecido), coincide con una coyuntura política y cultural en la que se resquebraja el consenso sobre ese pasado reciente, reconfigurando con ello el marco de lo decible y de lo investigable en esta materia. El campo político recupera el pasado reciente para hacerlo objeto de la política, apoyado en una interpretación de ese pasado que plantea profundas diferencias con la promovida por la transición democrática. ${ }^{15} \mathrm{Un}$ conjunto de figuras cobran protagonismo en la escena pública, como la del militante, la del desaparecido, la de los(as) hijos(as) de desaparecidos; y la interpretación oficial de nuestra historia abandona la "teoría de los dos demonios", para pasar a afirmar que uno de ellos no era tal, sino que se trataba de una generación de jóvenes comprometidos hasta la muerte con la transformación social de su país.

La impugnación de los académicos a la historia de divulgación puede interpretarse como un reflejo corporativo; parece entrar en juego para ello el sentido común del espacio académico que habitan, lo que Bourdieu denomina la doxa de un campo disciplinario. Pero además, como intentamos argumentar a lo largo de estas páginas, creemos que la sintonía entre la redefinición de la interpretación que desde el campo político se promueve de ese capítulo de nuestro pasado cercano, con un fenómeno editorial del género histórico que hace de "la omnipresencia de la última dictadura militar el hecho crucial

\footnotetext{
${ }^{15}$ En este sentido pueden entenderse los cambios introducidos por el gobierno de Néstor Kirchner en el año 2006 al prólogo de Nunca más, el libro que denuncia las desapariciones en la última dictadura, y que en su primera edición en 1984 había suscitado una polémica con los organismos de derechos humanos que veían en las palabras introductorias surgidas de la pluma de Ernesto Sábato una reivindicación a la "teoría de los dos demonios". En el texto, el escritor arrancaba: "Durante la década del 70, la Argentina fue convulsionada por un terror que provenía tanto desde la extrema derecha como de la extrema izquierda”. En 2006, por iniciativa del entonces gobierno de Néstor Kirchner, se propuso un cambio a la edición original que señalara, de antemano, "es preciso dejar claramente establecido, porque lo requiere la construcción del futuro sobre bases firmes, que es inaceptable pretender justificar el terrorismo de Estado como una suerte de juego de violencias contrapuestas como si fuera posible buscar una simetría justificatoria en la acción de particulares frente al apartamiento de los fines propios de la Nación y del Estado, que son irrenunciables". En defensa de la modificación, el entonces Secretario de Derechos Humanos, Eduardo Luis Duhalde, consideró que "el prólogo original no reproducía la filosofía política que hoy anima al Estado en la persecución de los crímenes de lesa humanidad" (Perfil, 30/04/2011).
} 
de todo nuestro pasado nacional" (Acha, 2008: 186), permite pensar en un proceso de reconfiguración de fuerzas en el plano político-intelectual que bien puede estar en la base de las reacciones de los académicos en contra de la historia que escriben los divulgadores. Hay a nuestros ojos una preocupación de carácter ideológico-político detrás de las intervenciones más duras de los académicos. Creemos que en lo que hace a esta dimensión del conflicto, la postura divergente que mantienen los contendientes en torno a la última dictadura militar es un factor central, porque la misma condensa dos miradas contrapuestas y extendidas en nuestro campo cultural sobre el periodo más traumático de la historia argentina. No porque la valoración de la última dictadura sea tan distinta para unos y otros, sino porque el modo en que los divulgadores la introducen en la historia da cuenta de las imágenes divergentes que estos dos grupos tienen de la historia y del modo en que debe ejercerse el oficio historiográfico.

En este sentido decimos que la última dictadura militar se constituye en un nudo temático. Creemos que el modo contrastante en que plantean cómo debe encararse la relación de la historia con la política, las dos tradiciones historiográficas en las que abrevan las posturas desplegadas en la disputa, son decisivos para producir modos de abordaje divergentes alrededor de la oscura historia vivida entre 1976 y 1983 en la Argentina. Los reparos metodológicos, epistemológicos y narrativos que imponen los criterios científicos bajo el influjo de los cuales trabajan los historiadores académicos, hacen del tratamiento de este tema, o bien una cuestión prohibida aún (por su cercanía temporal, por la tragedia política y humana que significó y porque en ese pasado están implicados los mismos historiadores que deberían tomarlo por objeto), o bien una cuestión que se aborda con arreglo a la despolitización adoptada por la profesionalización de la disciplina en los años ochenta; despolitización que, como ya señalamos, consistió en rigor en una repolitización, en virtud de la "estrategia democrática" que instruía a esos trabajos. En manos de la "historia militante", en cambio, la última dictadura militar es repuesta a la narrativa épica a la que es afecta este modelo, la cual devuelve la interpretación del periodo a sus cimientos más dramáticos y repone las motivaciones altruistas de aquellos que ofrecieron resistencia a la represión estatal, haciendo del traumático periodo algo distinto a la mera deformidad que asume la historia cuando se la piensa como obra de los demonios. En manos de los divulgadores "la omnipresencia de la última dictadura militar" se constituye en "el hecho crucial de todo nuestro pasado nacional" (Acha, 2008: 186), puesto que el mismo se transforma en el prisma desde el cual leen toda la historia argentina. 


\section{Los cánones historiográficos en disputa y sus regímenes de historicidad}

Hay otra problematización que puede realizarse de esta disputa conservando como dato el papel que tiene la última dictadura militar en el modo que ésta es recuperada (o no) por las tradiciones historiográficas en las que se inscribe la historia que escriben los contendientes. Nos referimos a un modo de entender la suerte desigual que ambas propuestas históricas tienen al ir al encuentro de un público que hace foco en sus regímenes de historicidad, es decir, en el orden temporal que prima en el discurso histórico de estos relatos.

Para ponderar la brecha existente en el tipo de acogida que el público dedica a estas dos opciones históricas creemos que resulta insoslayable atender al contexto en el que ésta se produce; y uno de los factores que todos los actores convienen en señalar como decisivo para comprender el porqué del interés masivo que despiertan los best-sellers en cuestión tiene que ver con la coyuntura de crisis en que éste se produce. Atender al contexto de recepción de estas obras es fundamental porque ciertos contenidos sólo hacen sentido o logran interpelar al lector si están dadas las condiciones para su recepción. Pero cuando proponemos atender al contexto de recepción no hacemos referencia sólo a un aspecto político y/o social sino también a una dimensión que impregna todo, que es la dimensión cultural; es decir, aludimos a los rasgos que asume la contemporaneidad que configuran los marcos de percepción y de significación de los productos simbólicos. De modo que el ejercicio que proponemos para aproximarnos a entender cuál es el secreto del éxito de masas experimentado por la historia de divulgación y cuál es la clave de la indiferencia sistemática que tributa el gran público a la historia académica, es analizar, con relación a su articulación con los contenidos y las formas concretas que proponen los dos modelos historiográficos, de qué manera pueden estar incidiendo algunas condiciones de la contemporaneidad en este impacto social desigual que tienen ambos modelos históricos. A su vez, creemos que la consideración de lo que aquí llamamos contemporaneidad, nos llevará indefectiblemente a analizar otro nivel del contenido de estas historias, que tiene que ver con la noción de régimen de historicidad acuñada por el historiador francés François Hartog $(2007$; 2010), que tiene la peculiaridad de preguntarse por el orden temporal que asume el discurso histórico, articulando este interrogante con una reflexión sobre cómo es experimentado el tiempo por la época de la que es hija ese discurso.

Empecemos por hacer un repaso sucinto de las características que asume cada uno de estos modelos históricos en relación con la forma que adoptan y el contenido que privilegian, a partir de lo cual estaremos en condiciones de analizar el tipo de régimen de historicidad que prima en ellos y de conjeturar 
cómo se lleva el orden del tiempo que pregonan estas obras con el modo en el que experimenta la temporalidad nuestra contemporaneidad.

Comencemos por la historiografía académica. Siguiendo el análisis propuesto anteriormente, lo que define a esta historiografía respecto de la evaluación histórica que propicia es, fundamentalmente, que tiene como faro el ideal del "país normal". La deformación del país a la que había contribuido la dictadura se contrapuso otro desde la imaginación historiográfica, que planteaba aspiraciones moderadas pero decididamente progresistas: "uno que desarrollara un modesto capitalismo, que soportara el pluralismo de partidos, defendiera una discreta redistribución de los ingresos y respetara los derechos humanos. En suma, se aspiró a un país normal" (Acha, 2008: 171). Este ideal, como ya dijimos, impregnó las convicciones políticas a la vez que modeló la institucionalización de la tarea intelectual que sobrevino tras los años de plomo. La consolidación del campo historiográfico se desarrolló con numerosas reflexiones y estudios que tenían como horizonte a una sociedad normalizada.

La "teoría de los dos demonios" había funcionado para el campo historiográfico como cerrojo, como una vuelta de página forzada de un capítulo dramático de nuestra historia que dejaba un vacío de sentido para el periodo, al decretar su sinsentido. Esa teoría dice: "ni los militares, ni los guerrilleros", "ni la dictadura, ni la revolución", y ceñida a esta formulación del conflicto cierra así la posibilidad de pensar las tramas que llevaron a las derivas violentas tomadas por la sociedad argentina en ese periodo.

Por otra parte, la legitimidad de la historia profesional estaba fundada en las prescripciones impuestas por la academia, lo cual redundaba en un discurso del pasado refractario para el gran público, puesto que está regido por valores científicos que hacen más engorrosa la construcción fluida de los textos, la inteligibilidad de los hechos que se cuentan y la implicación del lector en el relato. Asimismo, con el retorno de la democracia y las condiciones institucionales y políticas que ésta supone, la disciplina logra emprender el camino de la "normalización" y experimenta una profesionalización profunda (Pagano, 2010). Esto redunda en una mayor especialización y una creciente sofisticación de la disciplina. La fragmentación constituye el signo de estos tiempos para la historiografía, convirtiéndola en un territorio heterogéneo y dispar, marcado por la complejidad. En definitiva, se trató del proceso que la historiadora Nora Pagano caracterizó como de "estructuración hacia adentro y desestructuración hacia afuera" (Pagano, 2010: 50).

La evaluación histórica que promueven los divulgadores, en cambio, propone ubicar al país en un sitial distinto al del "país normal" propuesto por los académicos, y también difiere con ellos en su decidida indagación del pasado 
atenta a la necesidad de consagrar este ejercicio a la búsqueda de respuestas que urgen al presente. Tal como se constata en las críticas de los académicos en algunos estudios que analizan dichos best-sellers (Acha, 2008; Rodríguez, 2010), estos autores proponen una reconstrucción histórica que se informa por la fórmula "ayer es igual que hoy". De modo que lo que caracteriza a estas historias es que en su producción está ausente la idea de cambio social. En ellas la historia se vertebra a partir de la operación que homologa el pasado al presente, aplicando una lectura que tiende a asimilar el pasado al mundo actual, borrando así los condicionamientos de época que intervienen en el devenir histórico. Para ello incurren en anacronismos y proyecciones del sentido común del presente hacia el pasado, porque la interrogación al pasado está inspirada en los problemas del presente. Las categorías del presente se aplican al pasado, y el mismo termina adoptando un cariz muy parecido al de hoy, a partir del uso y abuso de figuras que hoy nos resultan familiares pero que son ajenas al mundo simbólico de la época a la que se aplican. Todo esto impide pensar el pasado en sus propios términos. Lo que habilita este tipo de lectura es una concepción de la historia que avanza por la lucha entre buenos y malos, por acción de héroes y villanos, prescindiendo de los procesos, las estructuras, los actores sociales.

El punto de la historia argentina que estos relatos toman como arquetipo, al cual adaptan muchas de las circunstancias de nuestro pasado y en el cual abrevan muchas de las figuras a las que apelan los divulgadores, es el periodo que comprende la última dictadura militar. Imágenes como la de los desaparecidos, los militares asesinos, los indultos, los 24 de marzo, aparecen aquí y allá, proyectando las connotaciones que las mismas encierran a una realidad difícilmente equiparable a la que están asociadas dichas imágenes. El estudio que el historiador Omar Acha realiza sobre las producciones históricas de Pigna y de Lanata lo lleva a sostener que la clave del éxito de sus trabajos está en el acento que estas historias ponen en la última dictadura militar, concentrándose especialmente en la práctica de desaparición de personas que ésta introdujo como política de Estado, haciendo de este hecho el eje articulador de toda la historia nacional, tanto hacia atrás como hacia adelante de la línea cronológica en la que se ubica el periodo militar 1976-1983. Al leer toda la historia argentina en esta clave, lo que operan estas narraciones es la eliminación de la idea de cambio social, los hechos que ingresan en esta historia son aquellos que son pasibles de ser articulados a partir de binomios equiparables a los que campeaban en la época más oscura de la Argentina. Acha ejemplifica el punto al que alude su tesis cuando reconstruye el modo en que presenta la historia Pigna, para quien: "Los pueblos originarios diezmados por la conquista fueron los primeros desaparecidos, así 
como Mariano Moreno fue arrojado al mar para hacer desaparecer su cuerpo temido por el saavedrismo reaccionario" (Acha, 2008: 184). En este sentido, si la historiografía académica hace una evaluación histórica en la que el "país normal" emerge como ideal para la historia argentina, la evaluación histórica que realizan los divulgadores los lleva a sostener la necesidad de incluir la memoria social en la historia.

Por otro lado, cabe consignar que las características que asumen las propuestas de los divulgadores que describimos anteriormente hace de esta historia un relato de fácil absorción para el lector porque, como dice Sarlo, "la repetición es un recurso de inteligibilidad, porque lo nuevo y lo desconocido se explican según las condiciones que se cree conocer bien, estableciendo una comparación implícita, gobernada por la analogía de lo diferente y lo conocido". ${ }^{16}$

A su vez, tanto algunas de las críticas de académicos como de las investigaciones que toman por objeto a las divulgaciones históricas que nos ocupan, señalan que las diferencias de forma y contenido que presenta con la historia académica tienen que ver con que las primeras no se escriben con arreglo a las reglas de la disciplina, como lo hace la segunda, y que el único protocolo que siguen es el que manda el mercado, esto es, vender y gustar al público (Semán, 2006; Acha, 2008; Rodríguez, 2010); para lo cual la mejor estrategia parece ser la de abandonar las rigideces conceptuales y recaudos interpretativos que valoran las instituciones académicas, dejar de lado el efecto de neutralidad en pos de un posicionamiento explícito del historiador que permita a los lectores identificar el punto de vista desde el que se está contando la historia y, en lo posible, una presentación sencilla del pasado, que esté a tono con los marcos interpretativos del presente desde el cual se lee la historia. A esto debe sumarse una retórica simple, el uso de un lenguaje llano y una hilación del relato de aprehensión sencilla.

Ahora bien, ambos relatos históricos, circulan en condiciones culturales particulares, y éstas siempre configuran una contemporaneidad que condiciona el modo en que son recibidos dichos relatos. Dicha contemporaneidad se define por un clima dominado por el fin de las certidumbres, la caída de los grandes relatos y los cambios de escala que imponen las derivas culturalistas. Algunos investigadores han señalado que el desdibujamiento de la idea de progreso que estos desplazamientos suponen ejerce efectos deflacionarios sobre las ideas de pasado y de futuro, produciendo una inflación del presente (Debord, 1995; Virno, 2003; Sibilia, 2008; Hartog, 2010). Lo que introducen estas transformaciones es un cambio en el modo en que nos 
relacionamos con el tiempo. En este sentido, cabe subrayar que la de tiempo es una categoría que varía temporoespacialmente, pues sus características se modifican al compás de los contextos y los cambios históricos. Siguiendo a Hartog podemos precisar que dicha contemporaneidad está marcada simultáneamente "por la caída del Muro de Berlín, por el desvanecimiento de la idea comunista basada en el porvenir de la Revolución y por el ascenso de múltiples fundamentalismos, perturbando de manera brutal y duradera nuestra relación con el tiempo" (Hartog, 2007: 21). También lo está por otra realidad que consiste en el reconocimiento de la diversidad de las culturas que comienza a configurarse a mediados del siglo pasado.

Asimismo, el carácter renovado que asume hoy la idea de tiempo también debe sus transformaciones a la globalización y al avance del género informativo (Hartog, 2010: 25) que, con sus ritmos fugaces y su presentación fragmentada, promueve la destemporalización y la destotalización (Sibilia, 2008: 154). La idea de destemporalización alude a un tiempo al que no le es inherente el pasado ni la promesa del futuro, es un tiempo sin tiempo porque en él el tiempo se comprime.

Estos cambios en la vivencia del tiempo constituyen la plataforma de emergencia del sentido común posmoderno que pregona "el fin de la historia" (Virno, 2003). La percepción actual del tiempo parece vaciada de contenido y significado histórico, su continuidad permanentemente interrumpida torna cada vez más difícil la acumulación o la reconstrucción progresiva y lineal de aquello que "llena" el tiempo, debilitando la experiencia histórica. El presente hoy es experimentado desde el instante y sin aquella carga temporal que lo ubicaba como punto de pasaje entre el pasado y el futuro. Es precisamente el andar ligero del presente y su conexión inmediata y a-histórica con el futuro lo que hace proclamar el derrumbe de la historia.

Paradójicamente, la pérdida de sentido histórico que supone nuestro presente se consustancia con una tendencia aparentemente contraria: la creciente reivindicación del pasado y la profusión de una cultura de la memoria (Huyssen, 2002). Se trata de dos caras de la misma moneda: la preocupación por el pasado y las actividades retrospectivas tienen como resorte la vivencia destemporalizada del presente: " el vigor de ese pasado rememorado en la duración de la propia experiencia vital — con su flujo de recuerdos y su objetivación del tiempo vivido- sólo podrá aumentar si el sujeto se encuentra inactivo; o sea, si son escasas sus necesidades e intereses ligados a la acción en el presente" (Sibilia, 2008: 144).

Si el modo en que la contemporaneidad vive el tiempo presenta divergencias con la concepción moderna del mismo, que se caracterizaba por el anudamiento entre pasado, presente y futuro, y a su vez constituyó la base a 
partir de la cual se organiza la historiografía moderna, ¿cuál es el papel que se espera que desempeñe el historiador en un mundo presentista? (Hartog, 2010) ¿Cómo se llevan con las nuevas condiciones de percepción del tiempo la historia que escriben académicos y divulgadores? Probablemente sea en las maneras diferentes de interactuar con las condiciones que presenta la contemporaneidad y con su manera de experimentar el tiempo donde reside la clave de la suerte de estos relatos del pasado.

¿Cuál es el orden del tiempo que parece primar en la historia académica según la imagen que nos devuelve de ella esta indagación?, ¿cuál es el régimen de historicidad por el que se rige? Por una lado, hay que señalar que la tendencia de la historiografía profesional consistente en la adaptación de sus enfoques a las renovaciones teóricas más innovadores que se están dando en algunos puntos de Europa y EUA (particularmente al giro antropológico, el retorno al sujeto y el neohistoricismo), produce un deslizamiento "de las estructuras a las redes de sociabilidad, de los sistemas de estratificación a las situaciones vividas, de la racionalidad global a las estrategias singulares, o sea, la manera a través de la cual los individuos producen el mundo social" (Pagano, 2010: 51). Esta desviación de lo nacional para tomar en cuenta lo económico y lo social en la historiografía profesional argentina, al igual que lo hizo la historiografía profesional en general en el resto de occidente (Hartog, 2007: 158) a la luz de la cual la nuestra se fue renovando, fue la manera - aunque indirecta - en que en este país la historiografía académica tomó nota de las transformaciones en las formas de experimentar el tiempo. ${ }^{17}$

Ahora bien, dentro de la historia académica hay autores que conservan la perspectiva nacional. ${ }^{18}$ En rigor son dichas historias las que constituyen una alternativa de la que escriben los divulgadores puesto que, como ellas, asumen a la Nación como eje vertebrador del relato. En este sentido, para responder a la cuestión del régimen de historicidad por el que se rige la historia académica resulta fructífero tener presente el papel que tiene la idea de "país normal" como ideal a alcanzar en sus relatos históricos. Porque si la tarea del historiador es la de "poner el presente en perspectiva" (Hartog,

${ }^{17}$ Habría que explorar si este desplazamiento de la Nación hacia la Sociedad por parte de la historia académica se acompañó de una diferente relación con el tiempo para el caso argentino. Para el caso francés el historiador Pierre Nora afirma que "la legitimación del pasado, por lo tanto de la historia, cedió el paso a la legitimación del futuro" (citado en Hartog, 2007: 158-159), es decir, que se trata de una historia que, a pesar de redefinir sus enfoques a la luz de la fragmentación que experimenta la idea de tiempo en el mundo contemporáneo, no deja por ello de organizarse a partir de un régimen moderno de historicidad.

${ }^{18}$ Incluso, entre aquellos en los que se detecta un desplazamiento hacia un registro del pasado desde una escala individual, hay casos en los que se mantiene la perspectiva nacional. 
2007: 14). Lo que ordena la perspectiva que adopta la historia académica es el punto de vista del porvenir, que en este caso se consustancia con la idea del "país normal". La inteligibilidad de la historia académica viene así del futuro, lo que le da sentido, lo que organiza la interpretación del pasado es su prospectiva, es la idea de "país normal" que se aspira para el futuro lo que proyecta su luz hacia el pasado organizando la historia en función de este telos. Por eso, el pasado reciente, la última dictadura militar, que sobresale por su deformidad y su excepcional brutalidad, nada tiene para contribuir en el camino hacia un "país normal", quedando así relegada de la matriz progresista que intenta reivindicar esta perspectiva y bajo la cual se coloca. En todo caso, en estos relatos históricos, esta etapa de nuestra historia es pensada como un interregno, ya que lo que se destaca es su anormalidad, lo cual, de cierta forma, también es una interpretación impregnada por el ideal del "país normal".

En suma, la historiografía académica, en coherencia con la tradición científica en la que se inscribe, produce un relato histórico sólidamente atado al concepto de progreso. Según la identificación que promueve Hartog, un tipo de tensión entre pasado, presente y futuro como la que propicia la historia académica es la típicamente moderna. Esta concepción está en sintonía con una idea lineal del tiempo en la que el pasado determina el presente, que a su vez genera el futuro.

¿Es compatible el régimen moderno de historicidad con la configuración del tiempo que se impone en la cultura contemporánea? ¿Es la condición presentista que caracteriza a nuestra época un marco de lectura propicio para las historias que se escriben bajo el régimen moderno de historicidad? El régimen moderno de historicidad, ¿es todavía funcional en el contexto de predominio hasta ahora inédito de la categoría del presente imperante?

Hartog opina que:

si la crítica del progreso no implica una promoción automática del presente, sí deja dudas sobre el carácter forzosamente positivo de la marcha hacia el porvenir [...] [Para él] el futurismo se hundió en el horizonte y el presentismo lo reemplazó. El presente se convirtió en el horizonte. Sin futuro y sin pasado, el presentismo genera diariamente el pasado y el futuro de quienes, día tras día, tienen necesidades y valoran lo inmediato (Hartog, 2007: 138, 140-141).

Cuando el porvenir se cierra, cuando el futuro se torna incierto, cuando la visión teleológica de la historia queda impugnada por las duraciones fugaces y efímeras que caracterizan los modos contemporáneos de vivir el tiempo, tanto por la imposibilidad de acumular experiencias progresivas en virtud de 
la creciente aceleración que sufre la historia como por la impugnación del sentido histórico del tiempo que esto implica, la luz proyectada desde el futuro disminuye y "el presente se convierte en la categoría preponderante, mientras que el pasado reciente - aquel del que nos sorprendemos que 'no pase' o del que nos inquietamos que 'pase' - exige incesante y compulsivamente ser visitado y revisitado" (Hartog, 2007: 168).

Ahora bien, no sólo la perspectiva desde la que se escribe la historia académica parece entrar en cortocircuito con el presentismo. También la profunda crisis que sobrevino en el año 2001 contorneó un escenario refractario a esa matriz historiográfica. Como ya sugerimos, esa crisis tuvo, además de ribetes políticos, sociales y económicos, un impacto cultural devastador. En tanto crisis cultural, el 2001 supuso para la Argentina "una suspensión del sentido común y del imaginario acerca de quiénes somos [...] es el periodo en el cual se produce una sensación colectiva de liminalidad, de que algo ha llegado a su fin, o de que un sentido crucial se ha tornado obsoleto..." (Grimson, 2011: 14).

En este sentido, el historiador Omar Acha sugiere la hipótesis de que el derrumbe de esa alianza representa mucho más que la caída de un gobierno. Para él, con ella "se quebrantó una idea del progreso nacional, y se fracturó la fuerza de convencimiento de la historia acuñada para examinar al 'país normal"'. Este escenario implica un agotamiento de las capacidades cognoscitivas de la historia académica. Las búsquedas y las demandas de nuevas narrativas que aporten sentido al devenir histórico que despierta una crisis de esta índole son las que explican, para este historiador, "el éxito del revisionismo light de Pigna y Lanata" (Acha, 2008: 194).

¿Qué régimen de historicidad prima en el tipo de evaluación histórica que promueven las producciones de Pigna, Lanata y O'Donnell? Como ya fue señalado, lo que prima en estos discursos históricos es la desaparición de la idea de cambio histórico. A su vez, se ha dicho que estas narraciones tienen cierto humor revisionista, al releer la historia nacional al calor de las heridas que deja nuestra última dictadura militar, haciendo uso del recurso de figuras asociadas al periodo ("desparecidos", "indultos", "24 de marzo") en circunstancias históricas que no tienen parangón con el llamado Proceso de Reorganización Nacional. La omnipresencia de la última dictadura militar funciona así como "el hito crucial de todo el pasado" (Acha, 2008: 186) en las narraciones históricas de los divulgadores.

La pregnancia que logran estas narraciones entre el gran público parece estar señalando, dice Acha, "la emergencia de un nudo temático que se impone como divisoria de una caracterización concentrada de lo nacional: la dictadura militar 1976-1983”. Si como sostiene este investigador, el nuevo nudo 
de la historia argentina es este periodo. ${ }^{19}$ Resulta verosímil plantear que el éxito de los divulgadores bien puede residir en haber reemplazado el ideal del país normal por el de la memoria social. Más verosímil aún si se tiene en cuenta que la revisión de la historia que promueven bajo las imágenes de la última dictadura militar encuentra en un mundo signado por el presentismo, y por un clima de época marcado por la memoria social que la hace objeto de políticas públicas, ${ }^{20}$ un ambiente propicio donde echar sus raíces. El régimen de historicidad que adoptan estas narraciones es entonces otro del moderno, que podríamos aventurar que responde a un régimen contemporáneo de historicidad, es decir, uno en el que el orden imperante es el presente, o bien, uno en el que sea el pasado de donde se extraen las lecciones de la historia, esto es, un régimen de historicidad antiguo, que descansa en la creencia de la historia como maestra de la vida (la historia magistra). ${ }^{21}$ Tanto en uno como en otro el pasado en tensión con el futuro deja de ser el eje de la narración histórica para concentrar su atención en la tensión que genera el pasado con el presente, esto es, un pasado concreto, que por las heridas abiertas que dejó en la sociedad reverbera en el presente, que como no logra procesarse vuelve como síntoma.

Lo cierto es que la historia de los divulgadores se desplaza, respecto de la que escriben los académicos, de lo prospectivo a lo retrospectivo, y de esa forma sacan el énfasis del futuro y lo ponen en el pasado. No se trata para los divulgadores de narrar a la Argentina una vez más, sino, más bien, de operar una ruptura con el relato convenido, preguntándose por el país ya no desde el ideal de normalidad sino interrogándolo a partir del presente, para intentar reencontrar en su pasado las respuestas a dichas preguntas. Lejos de ser teleológico, retroactivamente teleológico, su recorrido es regresivo.

Si la historia vertebrada a partir del ideal de "país normal" supo prestarse a un uso político en el marco de la transición democrática, la configuración contemporánea propicia condiciones de producción y de recepción para una

${ }^{19}$ Que además se constata en la inflación que se observa en las investigaciones surgidas en el ámbito universitario dedicadas al periodo. Asimismo, creemos que la hipótesis de Acha cobra fuerza si se tiene en cuenta que quienes ocupan el poder de gobernar a escala nacional desde el año 2003 han reinstalado el pasado reciente en la agenda política por medio de medidas como la derogación de las leyes de Indulto y de Obediencia Debida y Punto Final, de políticas de la memoria y al apoyo estatal que han brindado a los organismos de derechos humanos, entre otras.

${ }^{20} \mathrm{Y}$ esta tendencia se extiende en buena parte de Europa. Véanse Hartog (2010), y Nora (2001) para el caso francés, y Huyssen (2002) para el alemán.

${ }^{21}$ En la base de este modelo por el cual la historia puede ser una fuente de sabiduría para la vida existe una concepción de la misma desprovista de la idea de tiempo como cambio. La estabilidad y la continuidad sería lo que caracteriza al tiempo para este modelo, que entonces debe apelar a argumentos de tipo providenciales para explicar los cambios en la historia (Palti, 2004: 68-69). 
historia que retorna al pasado para saldar las cuentas que la historiografía profesional dejó pendientes. Y la peculiaridad que parece distinguir a estas narraciones de alcance masivo es su intención de conciliar historia con memoria, de plantear un pacto entre historia y memoria que está ausente en la historiografía académica.

\section{A modo de cierre}

Los clivajes que a lo largo de su historia muestra la práctica de la disciplina historiográfica en la Argentina coinciden con las inflexiones que se producen en su historia política. El parentesco entre crisis y renovación historiográfica está, como vimos, demostrado para el caso argentino: la llamada "década infame" produjo en los años treinta una vacancia historiográfica que capitalizaron los revisionismos históricos; la caída del peronismo en 1955 se intentó explicar desde la historia promoviendo distintas miradas: por un lado, emergen los nuevos revisionismos de izquierda, y por otro se institucionaliza en la universidad la renovación historiográfica impulsada por José Luis Romero; el retorno a la democracia tras la última dictadura militar, por su parte, retoma la interrupción del ciclo romeriano iniciada en el 55 y avanza hacia la profesionalización de la disciplina, "vertido en la fórmula del país normal" (Acha, 2008: 194). La profunda crisis que sacudió a la Argentina ni bien comenzamos a transitar este nuevo siglo propició nuevas búsquedas, nuevas demandas de narrativas históricas tras la crisis del régimen de significación que hasta entonces otorgaba certidumbres a la sociedad. En esta oportunidad "la disponibilidad" fue aprovechada por lo que aquí llamamos "los libros de la controversia", un conjunto de best-sellers históricos que rompen con el divorcio de la historia y la memoria e incluyen a esta última en sus narrativas históricas, sin prestar atención a los reparos que pone a ello las reglas de la disciplina.

Este parentesco entre crisis y renovación historiográfica da cuenta del carácter político del discurso historiográfico, de su inherente politicidad. Y esta condición hace de la historia un instrumento de la política, hace de su objeto, el pasado, objeto de uso político.

Según vimos, el centro de las disputas por el pasado lo constituye el periodo de la última dictadura militar, puesto que es este el nudo de la historia argentina que activa evaluaciones históricas divergentes: para unos inspira el ideal del país normal a partir del cual leen toda la historia nacional, mientras que para otros este hecho se constituye en el hecho crucial de todo nuestro pasado nacional. La imaginería histórica que activan los primeros 
es la que domina entre los historiadores académicos, que se inscriben en la matriz historiográfica científica y organizan sus relatos sobre el pasado a partir de un régimen moderno de historicidad, es decir, con el acento puesto en el futuro, en la sociedad normalizada por venir. La evaluación histórica que promueven los segundos, en cambio, es la que está presente entre los divulgadores de la historia, que abrevan en el modelo militante de la historia y asumen un régimen de historicidad distinto del que instruyó la modernidad, puesto que en estas narraciones históricas el orden del tiempo que impera ya no es el futuro, sino que es un vaivén entre el presente y el pasado del que es difícil decidir cuál se sobrepone como faro a partir del cual se realizan las evaluaciones de la historia.

Recibido: agosto de 2013

Revisado: noviembre de 2013

Correspondencia: Chile 1547/Ciudad Autónoma de Buenos Aires/CP 1100/ Argentina/correo electrónico: verotobena@gmail.com

\section{Bibliografía}

Acha, O. (2012), Un revisionismo histórico de izquierda. Y otros ensayos de política intelectual, Buenos Aires, Herramienta.

Acha, O. (2009), Historia crítica de la historiografía argentina: las izquierdas en el siglo $X X$, Buenos Aires, Prometeo.

Acha, O. (2008), "Las narrativas contemporáneas de la historia nacional y sus vicisitudes", en O. Acha, La nueva generación intelectual. Incitaciones y ensayos, Buenos Aires, Herramienta, pp. 169-194.

Canavese, Mariana e Ivana Costa (2005), "Entrevista a Tulio Halperin Donghi. La serena lucidez que devuelve la distancia", Ñ. Revista de Cultura, núm. 87, 28 de mayo, pp. 6-9.

Carretero, M., A. Rosa y M. F. González (2006), "Introducción. Enseñar historias en tiempos de memoria", en M. Carretero, A. Rosa y M. F. González, Enseñanza de la historia y memoria colectiva, Buenos Aires, Paidós.

Carretero, M. y J. F. Voss (dirs.) (2004), Aprender y pensar la historia, Buenos Aires, Amorrortu.

Cattaruzza, A. (2007), Los usos del pasado. La historia y la política argentinas en discusión, 1910-1945, Buenos Aires, Sudamericana.

Cernadas, J. y D. Lvovich (2010), “Revisitas a la pregunta: historia ¿para qué?”, en J. Cernadas y D. Lvovich (eds.), Historia, ¿para qué? Revisitas a una vieja pregunta, Buenos Aires, Prometeo.

Debord, G. (1995), La sociedad del espectáculo, Buenos Aires, La Marca. 
Devoto, F. J. (2010), "Prefacio", en F. J. Devoto (dir.), Historiadores, ensayistas y gran público. La historiografia argentina, 1990-2010, Buenos Aires, Biblos.

Devoto, F. J. y N. C. Pagano (2009), Historia de la historiografia argentina, Buenos Aires, Sudamericana.

Di Meglio, G. (2012), "Para una nueva discusión sobre nuestra historiografía académica", blog de acceso libre, La historia en cuestión. Historia y Política en tiempos kirchneristas, 29 de mayo, en URL: http://historiaencuestion.blogspot. com.ar/2012/05/para-una-nueva-discusion-de-nuestra.html, fecha de consulta julio de 2013.

Fernández, C. J. (2012), "Relatar el pasado, relatar el presente", blog de acceso libre, El pingüino de Minerva, 16 de julio, en URL: http://elpinguinodeminerva.wordpress.com/2012/07/16/relatar-el-pasado-relatar-el-presente/, fecha de consulta julio de 2013.

Foucault, M. (2000), Defender la sociedad, Buenos Aires, FCE.

Gelman, Jorge (2007), "De héroes y villanos", Página/12, 30 de octubre.

Grimson, A. (2011), Los límites de la cultura. Crítica de las teorías de la identidad, Buenos Aires, Siglo XXI.

Hartog, F. (2010), "El historiador en un mundo presentista", en F. J. Devoto (dir.), Historiadores, ensayistas y gran público. La historiografia argentina, 19902010, Buenos Aires, Biblos.

Hartog, F. (2007), Regímenes de historicidad: presentismo y experiencias del tiempo, México, Departamento de Historia-Universidad Iberoamericana.

Huyssen, A. (2002), En busca del futuro perdido. Cultura y memoria en tiempos de globalización, México, FCE.

Jelin, E. (2001), "Historia, memoria social y testimonio o la legitimidad de la palabra", Iberoamericana. América Latina-España-Portugal, núm. 1, año I, pp. 87-98.

Mendelevich, Pablo (2005), "Hazañas de ayer y de hoy", La Nación, 11 de diciembre.

Myers, J. (2004), "Pasados en pugna: la difícil renovación del campo histórico argentino entre 1930 y 1955", en F. Neiburg y M. Plotkin (comps.), Intelectuales y expertos. La constitución del conocimiento social en la Argentina, Buenos Aires, Paidós.

Nora, P. (2001), Les lieux de mémoire, París, Gallimard.

Pagano, N. C. (2010), "La producción historiográfica reciente: continuidades, innovaciones, diagnósticos", en F. J. Devoto (dir.), Historiadores, ensayistas y gran público. La historiografía argentina, 1990-2010, Buenos Aires, Biblos.

Palomar, Jorge (2005), "En torno de la verdad", entrevista a Luis Alberto Romero y Miguel Ángel de Marco, La Nación, 30 de abril.

Palti, E. J. (2004), "Koselleck y la idea de Sattelzeit. Un debate sobre modernidad y temporalidad", Ayer, núm. 53.

Paredes, Rogelio (2005), "El pasado en versión 'no oficial”, La Nación, 12 de junio.

Pittaluga, R. (2010), "Notas sobre la historia del pasado reciente", en J. Cernadas y D. Lvovich, (eds.), Historia, ¿para qué? Revisitas a una vieja pregunta, Buenos Aires, Prometeo. 
Rodríguez, M. (2010), "Los relatos exitosos sobre el pasado y su controversia. Ensayistas, historiadores y gran público, 2001-2006”, en F. J. Devoto (dir.), Historiadores, ensayistas y gran público: la historiografía argentina, 19902010, Buenos Aires, Biblos.

Romero, Luis Alberto (2003), "Sobre el ser nacional”, La Nación, 29 de junio.

Romero, Luis Alberto (2004a), “Una visión muy personal”, La Nación, 20 de junio. Romero, Luis Alberto (2004b), "Neo-revisionismo de mercado", Ñ. Revista de Cultura, núm. 66, 31 de diciembre, p. 26.

Romero, Luis Alberto (2004c), "La historia en la Escuela”, La Nación, 3 de marzo. Romero, Luis Alberto (2004d), "Mercaderes de la historia”, La Nación, 24 de febrero. Sabato, Hilda y Mirta Lobato (2005), "Falsos mitos y viejos héroes", Ñ. Revista de Cultura, núm. 118, 31 de diciembre, pp. 12-13.

San Martín, Raquel (2007), "La historia académica, al contraataque", La Nación, 11 de octubre.

Sarlo, B. (2006), "Historia académica vs. Historia de divulgación”, La Nación, 22 de enero.

Sarlo, B. (2001), "Ya nada será igual", Punto de Vista, núm. 70, año XXIV.

Sarlo, B. (1994), "Entrevista a Beatriz Sarlo”, en R. Hora y J. Trímboli, Pensar la Argentina. Los historiadores hablan de historia y politica, Buenos Aires, El Cielo por Asalto.

Sarlo, B. (1985), “Intelectuales: ¿escisión o mímesis?”, Punto de Vista, núm. 25, año VII.

Sazbón, D. (2012), “Cruces”, blog de acceso libre, La historia en cuestión. Historia y Política en tiempos kirchneristas, 30 de marzo, en URL: http://historiaencuestion. blogspot.com.ar/2012_03_01_archive.html, fecha de consulta julio de 2013.

Semán, P. (2006), "Historia, best sellers y política”, en P. Semán, Bajo continuo. Exploraciones descentradas sobre cultura popular y masiva, Buenos Aires, Gorla.

Semán, P., B. Lewgoy y S. Merenson (2007), "Intelectuales de masas y Nación en Argentina y Brasil”, en Alejandro Grimson (comp.), Pasiones nacionales: politica y cultura en Brasil y Argentina, Buenos Aires, Edhasa.

Sibilia, P. (2008), La intimidad como espectáculo, Buenos Aires, FCE.

Torre, J. C. (2004), “Los intelectuales y la experiencia democrática”, en M. Novaro y V. Palermo (comps.), La historia reciente: Argentina en democracia, Buenos Aires, Edhasa.

Virno, P. (2003), El recuerdo del presente. Ensayo sobre el tiempo histórico, Buenos Aires, Paidós.

Williams, R. (1980), Marxismo y literatura, Barcelona, Península.

\section{Acerca de la autora}

Verónica Tobeña es doctora en ciencias sociales por la Flacso-Argentina. Es investigadora y docente del área de educación de esa misma institución. 
Sus áreas de interés son el análisis de los campos literario, historiográfico y educativo desde la perspectiva de la sociología de la cultura. De sus publicaciones podemos citar " ¿Vale todo en la literatura? El juego del campo literario argentino", Trabajo y Sociedad. Sociología del trabajo, Estudios culturales, Narrativas sociológicas y literarias, núm. 22, verano, 2014, en prensa; así como "La cuestión del canon en la literatura argentina. Un campo cultural abierto en dos", A Contra Corriente. Una Revista de Historia Social y Literatura de América Latina, vol. 9, núm. 2, invierno, 2012, pp. 282-318. 
